\title{
Ação Alelopática de Extratos de Embaúba (Cecropia pachystachya) No CRESCIMENTO DE CAPIM-ColoniÃo (Panicum maximum) ${ }^{1}$
}

\author{
Allelophatic Action of Cecropia pachystachya Extracts on the Growth of Guinea Grass \\ (Panicum maximum)
}

\author{
HERNÁNDEZ-TERRONES, M.G. ${ }^{2}$, MORAIS, S.A.L. ${ }^{3}$, LONDE, G.B. ${ }^{4}$, NASCIMENTO, E.A. ${ }^{5}$ e \\ CHANG, R. ${ }^{6}$
}

\begin{abstract}
RESUMO - Cecropia pachystachya (embaúba) é uma planta da família Urticaceae, característica de margens de florestas. Possui rápido desenvolvimento e é abundante em todo o território brasileiro. Neste estudo, foram analisados os potenciais alelopáticos dos extratos metanólicos da casca, do tronco e das raízes da embaúba por meio de bioensaios de germinação e medida do desenvolvimento da parte aérea do capim-colonião (Panicum maximum). O maior efeito foi observado no extrato das raízes na concentração de $150 \mathrm{ppm}$. Os principais constituintes voláteis identificados por CG/EM foram: na casca: geranilacetona, ácido láurico, ácido palmítico, octadecanal e alcanos de cadeia longa; nas raízes: geranilacetona, farnesol, farnesilacetona, ácido palmítico, octadecanal e alcanos de cadeia longa; e no tronco: geranilacetona, ácido palmítico e alcanos de cadeia longa.
\end{abstract}

Palavras-chave: atividade alelopática, compostos voláteis, extrato metanólico.

\begin{abstract}
Cecropia pachystachya (embauba) is a tree of the Urticaceae family, typical of forest margins. It grows quickly and is abundant throughout Brazil. In this study, the allelophatic potential of the methanolic extracts from the bark, trunk and roots of Cecropia pachystachya cultivated in Uberaba, Minas Gerais, Brazil was analyzed through germination bioassays and growth measurements of the aerial part of Panicum maximum. The best effect was observed in the root extracts at $150 \mathrm{ppm}$ concentration. The following main volatile constituents were identified by GC/MS: geranylacetone, lauric acid, palmitic acid, octadecanal and long chain alkenes in the bark; geranylacetone, farnesol, farnesylacetone, octadecanal, palmitic acid and long-chain alkenes in the root; and geranylacetone, palmitic acid and long-chain alkenes in the wood.
\end{abstract}

Keywords: allelophatic activity, volatile compounds, methanolic extract.

Recebido para publicação em 8.12.2006 e na forma revisada em 25.10.2007.

2 Professor Associado I do Instituto de Química - Universidade Federal de Uberlândia, Avenida João Naves de Ávila, 2121, Uberlândia - MG, 38408-100, <mhernandez@iqufu.ufu.br>; ${ }^{3}$ Professor Associado I do Instituto de Química - Universidade Federal de Uberlândia, Avenida João Naves de Ávila, 2121, Uberlândia - MG, 38408-100, <salemos@ufu.br>; ${ }^{4}$ Mestre pelo Instituto de Química - Universidade Federal de Uberlândia, Avenida João Naves de Ávila, 2121, Uberlândia - MG, 38408-1 00, $<$ londe@centershop.com.br>; ${ }^{5}$ Professor Titular Aposentado e Pesquisador Voluntário do Instituto de Química - Universidade Federal de Uberlândia, Avenida João Naves de Ávila, 2121, Uberlândia - MG, 38408-100, <eanascimeto@ufu.br>; ${ }^{6}$ Professor Substitu to do Instituto de Química - Universidade Federal de Uberlândia, Avenida João Naves de Ávila, 2121, Uberlândia - MG, 38408-100,<chang@iqufu.ufu.br>. 


\section{INTRODUÇÃO}

Os produtos naturais obtidos de matériaprima vegetal oferecem larga variedade de moléculas com grande diversidade nas suas estruturas e atividade biológica. Esta atividade pode se manifestar por meio das suas propriedades herbicidas, inseticidas, fungicidas e/ou farmacológicas (Reigosa \& Pedrol, 2002; Simões et al., 2002; Hernández-Terrones et al., 2003).

Existe uma literatura considerável sobre o comportamento alelopático dos vegetais. O termo alelopatia é usado para indicar qualquer efeito causado por um ser vivo de forma benéfica e/ou prejudicial sobre outro, por meio da liberação de substâncias químicas denominadas aleloquímicos. Estes são liberados pelas diversas partes da planta ou por intermédio da decomposição de folhas e caules e exsudação direta no solo pelas raízes (Rice, 1984; Mizutani, 1999).

As plantas têm o seu próprio mecanismo de defesa, e os aleloquímicos, algumas vezes, podem ser considerados "herbicidas naturais". Os aleloquimicos isolados de plantas ou microrganismos são uma fonte potencial para modelos de novos tipos estruturais de herbicidas. Esses "herbicidas naturais" podem ser mais específicos, com novos modos de ação e de maior potencial que aqueles usados atualmente na agricultura (Mizutani, 1999; Duke et al., 2000). Dessa forma, a alelopatia pode ajudar, fornecendo novos conceitos de controle integrado de plantas daninhas, variedades de culturas e novas gerações de fitotoxinas (Zimdhal, 1999; Vyvyan, 2002).

A Cecropia pachystachya (embaúba), também conhecida pelos nomes de umbaúba, imbaúba, embaúva, umbaúba-do-brejo, árvore-dapreguiça, umbaubeira, pau-de-lixa, umbaúbabranca, árvore-da-preguiça, entre outras (Hikawczuk et al., 1998; Hashimoto, 2002), é característica de solos de maior umidade, típica da borda de matas, clareiras grandes e de estradas e tem preferência pelos locais ensolarados, sendo rara sua presença no interior de matas fechadas. Floresce de setembro a outubro e frutifica de maio a junho. O desenvolvimento das plantas no campo é rápido. Os frutos são procurados pelas aves e servem de alimento a várias espécies de peixes, como pacu, piracanjuba e outros (Balbachas, 1960).
Essa planta se distribui desde o México até a Argentina. No Brasil, situa-se principalmente no litoral do Nordeste, passando por Sudeste, Centro-Oeste e chegando até Santa Catarina. Está presente tanto na área dos cerrados quanto na de florestas variadas e formações do complexo atlântico (ESALQ - USP, 2003). Segundo Lorenzi (1998), a madeira de embaúba, em condições adversas, é extremamente suscetível ao ataque de organismos xilófagos (bactérias, fungos etc.). É muito usada no tratamento de diabetes, tosse, bronquite e apresenta poderoso efeito diurético.

Como essa planta é nativa em toda a região Sudeste, ocorrendo, com abundância, às margens de florestas nativas ou em recomposição destas, provavelmente, deve dominar com facilidade a competição com outras plantas, incluindo espécies vegetais daninhas, seja por interferência direta ou por efeitos alelopáticos. Portanto, este trabalho teve como objetivo verificar a ação alelopática dos extratos metanólicos de casca, tronco e raízes da embaúba sobre a germinação de sementes e o crescimento de Panicum maximum (capim-colonião). Foi analisada, também, a composição química dos óleos essenciais de tronco, casca e raízes.

\section{MATERIAL E MÉTODOS}

Os solventes químicos usados foram de grau analítico.

\section{Preparação das amostras}

As amostras de embaúba foram coletadas no municipio de Uberaba-MG. Elas foram colhidas em três regiões diferentes, diretamente no campo, onde proliferam naturalmente. No presente estudo, três indivíduos de aproximadamente cinco anos de idade e DAP (diâmetro à altura do peito) de $12,0 \mathrm{~cm}$ foram colhidos. Essas amostras foram transformadas em troncos, os quais foram cortados na altura correspondente de 25,0 $\mathrm{cm}$ da base até a 1,3 $\mathrm{m}$ (DAP). Esses troncos foram descascados e transformados em discos de 2,0 cm, moídos em um moinho de bolas de porcelana; a serragem resultante, tanto dos troncos quanto das cascas, foi peneirada com peneira de 40 mesh. As raízes também foram moídas. 


\section{Caracterização alelopática}

Este estudo foi conduzido em ambiente estéril, com controle de luminosidade e temperatura constante, onde sementes da espécie escolhida como alvo foram testadas para se verificar a porcentagem de germinação e o desenvolvimento das plantas germinadas. Dessa forma, avaliou-se o grau de interferência das substâncias químicas presentes nos extratos da espécie em estudo (embaúba) sobre a germinação e o crescimento da parte aérea de Panicum maximum (capim-colonião) (Duke et al., 1998; Hernández-Terrones et al., 2003).

Placas de Petri foram utilizadas como miniestufas estéreis, nas quais foram controladas a temperatura, a umidade e a luminosidade. Todo o material - vidraria, reagentes, capela de fluxo laminar e outros - foi esterilizado. Cerca de 400,00 g de cada material (tronco, raiz e casca) foram colocados em imersão em 2,00 L de metanol PA e deixados em repouso, com agitações periódicas para extração, durante 48 horas. Após esse período, cada material foi filtrado e o solvente recuperado em um evaporador rotativo. Os extratos então obtidos foram diluídos em água deionizada para as concentrações de 50, 75, 100 e 150 ppm.

Em cada unidade experimental - placas de Petri esterilizadas - adicionaram-se os extratos e, em seguida, 60 sementes, com quebra de dormência. Esse procedimento foi realizado sempre com três repetições (triplicata) e mantido com fotoperiodo de oito horas e temperatura constante de $25^{\circ} \mathrm{C}$, em ambiente estéril durante 18 dias, em condições de igualdade para todas as placas. Cada placa foi envolvida por um filme plástico transparente, para manter a integridade do ambiente estéril, a concentração de umidade e os valores homogêneos de temperatura.

Os resultados obtidos, referentes ao número de sementes germinadas e ao tamanho da parte aérea das plantas germinadas, foram comparados com a unidade experimental de referência, que foi preparada nas mesmas condições, porém isenta de extratos.

\section{Extração do óleo essencial}

Foi utilizado um aparelho de Clevenger para extração. Cerca de 5,00 g de amostras (tronco, raiz ou casca) foram colocados imediatamente no balão de destilação com 100,00 mL de água destilada. Após duas horas, a destilação foi interrompida e o óleo essencial extraído com três extrações de $5,00 \mathrm{~mL}$ de diclorometano, que, em seguida, foi concentrado, por meio de destilação a pressão reduzida, para 1,00 mL.

\section{Cromatografia gasosa acoplada à espectrometria de massas (CG/EM)}

A cromatografia gasosa acoplada à espectrometria de massas foi feita num aparelho da marca Shimadzu, modelo GC17A/QP5000.

Foi usada uma coluna do tipo capilar de sílica fundida com fase estacionária $\mathrm{DB}-5$, de $30 \mathrm{~m}, 0,25 \mathrm{~mm}$ de d.i. e $0,25 \mu \mathrm{m}$ de filme, utilizando hélio como gás carreador. O programa de temperatura foi de $60-240{ }^{\circ} \mathrm{C}\left(3^{\circ} \mathrm{C} \mathrm{min}{ }^{-1}\right)$ e $240{ }^{\circ} \mathrm{C}$ (20 $\left.\mathrm{min}\right)$. A energia de impacto foi de $70 \mathrm{eV}$ e foram captados os fragmentos de $40 \mathrm{a}$ 650 u. Um $\mu \mathrm{L}$ de amostra, dissolvido em diclorometano, foi injetado manualmente. A identificação dos compostos foi feita por meio das bibliotecas de espectros de massas da Wiley (330.000 espectros) e por índices de Kovat (Adams, 2001).

\section{Análises estatísticas}

Os resultados dos experimentos de germinação e crescimento foram obtidos em triplicata, sendo calculado o desvio-padrão e aplicado o parâmetro do teste t de Student com probabilidade de $95 \%$.

\section{RESULTADOS E DISCUSSÃO}

O potencial fitotóxico dos extratos metanólicos de tronco, casca e raízes da embaúba foi verificado por meio de bioensaios de germinação e desenvolvimento da parte aérea de capim-colonião.

A Figura 1 apresenta o gráfico do comportamento alelopático dos extratos na germinação das sementes.

Na Figura 2 é mostrado o gráfico do comportamento alelopático dos extratos sobre o crescimento do capim-colonião.

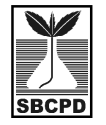




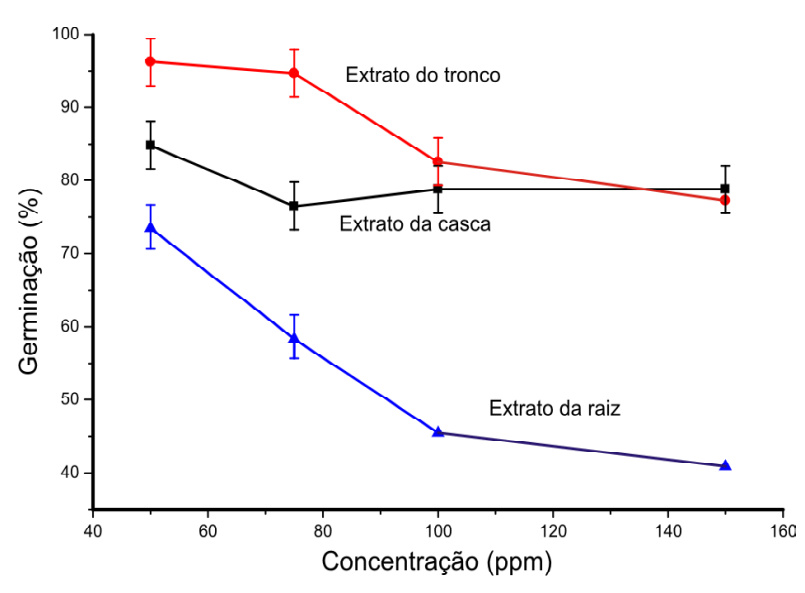

Figura 1 - Gráfico comparativo do comportamento alelopático dos extratos de embaúba na germinação de sementes de capim-colonião.

Os extratos do tronco e casca apresentaram discreto efeito sobre a germinação das sementes até $75 \mathrm{ppm}$. Entre 50 e $75 \mathrm{ppm}$ os extratos da casca alcançaram a maior inibição $(23,5 \%)$. Acima disso, a inibição estacionou em $21,2 \%$. O extrato do tronco apresentou o melhor efeito inibitório sobre a germinação das sementes somente na concentração de 150 ppm $(22,7 \%)$. O extrato da raiz provocou maior inibição do que os extratos anteriores na germinação das sementes em todas as concentrações; a inibição aumentou com a concentração, alcançando $59,1 \%$ a $150 \mathrm{ppm}$.

O efeito dos extratos de embaúba sobre o desenvolvimento das sementes de capim-colonião germinadas foi ligeiramente mais acentuado do que sobre a germinação de sementes, aumentando sempre com a concentração. No crescimento da parte aérea, usando-se extrato metanólico de tronco, casca e raízes, as inibições foram de $26,2,36,9$ e $63,5 \%$, respectivamente, na concentração de 150 ppm.

\section{Constituintes voláteis}

A Tabela 1 apresenta os compostos identificados por CG/EM no óleo essencial de tronco, casca e raízes da madeira de embaúba obtido por extração do arraste de vapor no aparelho de Clevenger; as Figuras 3, 4 e 5 apresentam os perfis dos cromatogramas obtidos.

No tronco, a concentração do óleo essencial foi muito pequena e os principais constituintes

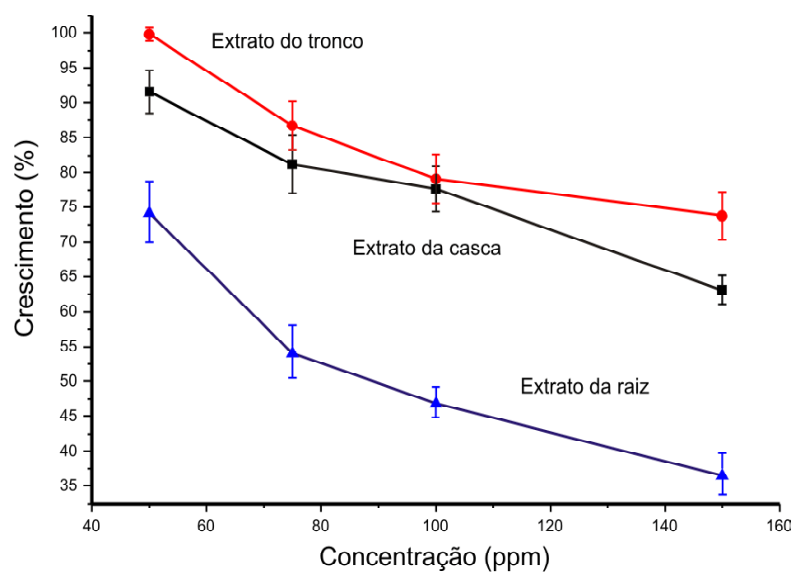

Figura 2 - Gráfico comparativo do comportamento alelopático dos extratos de embaúba no desenvolvimento da parte aérea de capim-colonião.

voláteis identificados por CG/EM foram: geranilacetona, ácido palmítico e alcanos de cadeia longa; na casca: geranilacetona, ácido láurico, ácido palmítico, ácido oléico, octadecanal e alcanos de cadeia longa; e nas raízes: geranilacetona, farnesol, dodecanal, farnesilacetona, ácido palmítico, octadecanal e heneicosano.

Portanto, pela técnica de extração do óleo essencial por arraste de vapor no aparelho de Clevenger, com a quantidade de madeira usada e o limite de detecção estipulado $(\geq 1,0 \%)$, a composição química do óleo essencial das raízes apresentou constituintes químicos que não foram detectados na casca ou no tronco, como farnesol, farnesilacetona e octadecanal, que podem estar contribuindo para o maior efeito alelopático desse extrato.

Além desses constituintes do óleo essencial, muitos outros compostos pouco voláteis certamente estão presentes no extrato metanólico tanto do tronco quanto da casca e das raizes e ainda precisam ser investigados.

Os efeitos sobre a germinação e o desenvolvimento das sementes de capim-colonião provocados pelos extratos da casca e do tronco da embaúba foram muito parecidos, sendo o da casca um pouco superior.

Os efeitos sobre a germinação e o desenvolvimento das sementes de capim-colonião ocasionados pelo extrato de raízes foi superior em todas as concentrações. O maior efeito foi 
Tabela 1 - Compostos identificados por CG/EM no óleo essencial de tronco, casca e raízes de embaúba

\begin{tabular}{|c|c|c|c|}
\hline \multirow{2}{*}{ Picos } & Tronco & Casca & Raizes \\
\cline { 2 - 4 } & Geranilacetona & Geranilacetona & Neranilacetona \\
\hline 1 & Ácido palmítico & Dodecano & Farnesol \\
\hline 3 & Contaminante & Tetradecano & Dodecanal \\
\hline 4 & N.i. & Ácido láurico & N.i. \\
\hline 5 & Tricosano & Contaminante & N.i. \\
\hline 6 & Contaminante & Ácido palmítico & Contaminante \\
\hline 7 & Alcanos com mais de 25 carbonos & Contaminante & Farnesilacetona \\
\hline 8 & & N.i. & Ácido palmítico \\
\hline 9 & & Octadecanal & N.i. \\
\hline 10 & & N.i. & N.i. \\
\hline 11 & & Ścido oléico & Octadecanal \\
\hline 12 & & N.i. & IIeneicosano \\
\hline 13 & & Hencicosano & N.i. \\
\hline 14 & & N.i. & Contaminante \\
\hline 15 & & Tricosano & \\
\hline 16 & & Contaminante & \\
\hline
\end{tabular}

N.i. = não identificado.

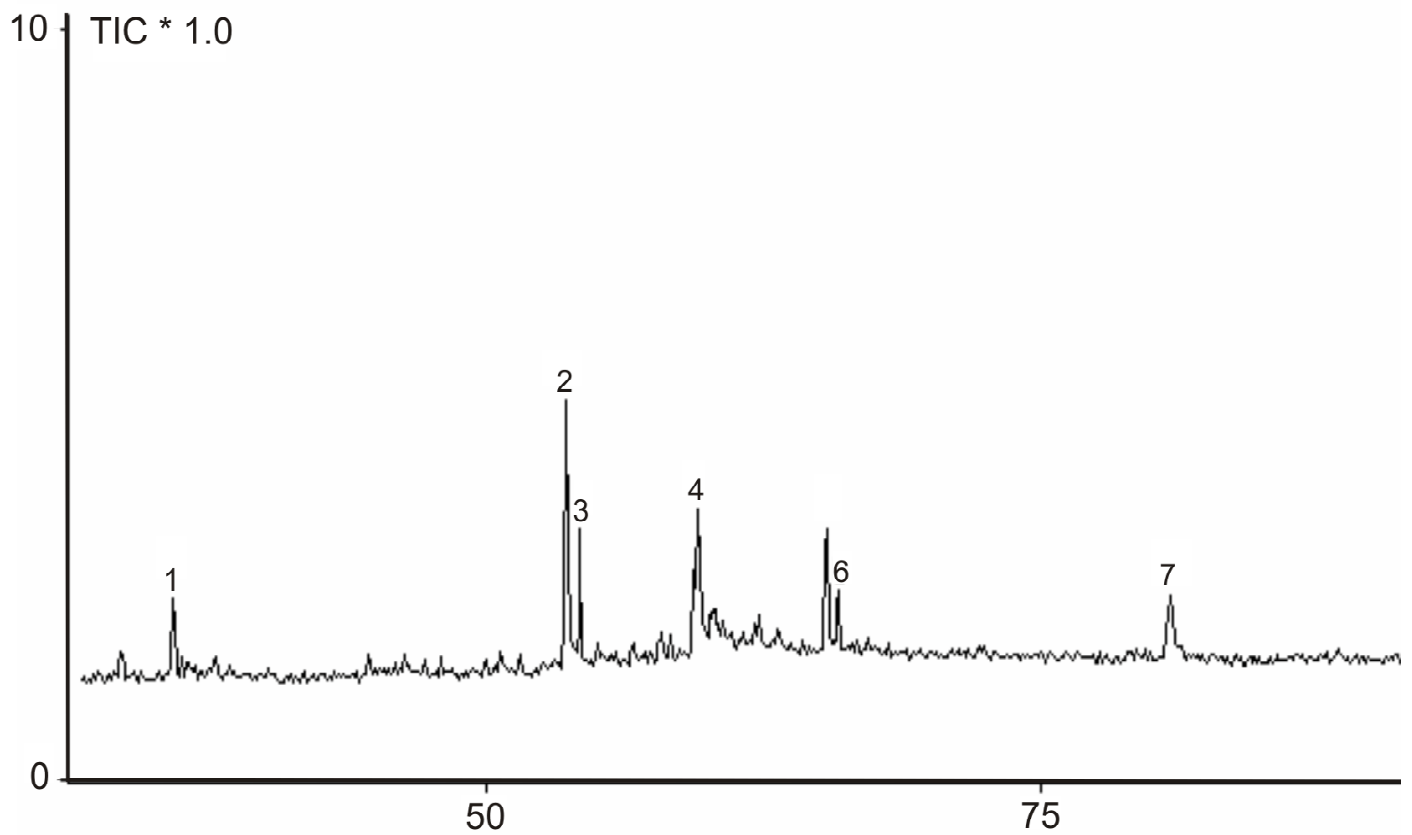

Figura 3 - Cromatograma do óleo essencial do tronco de embaúba. 


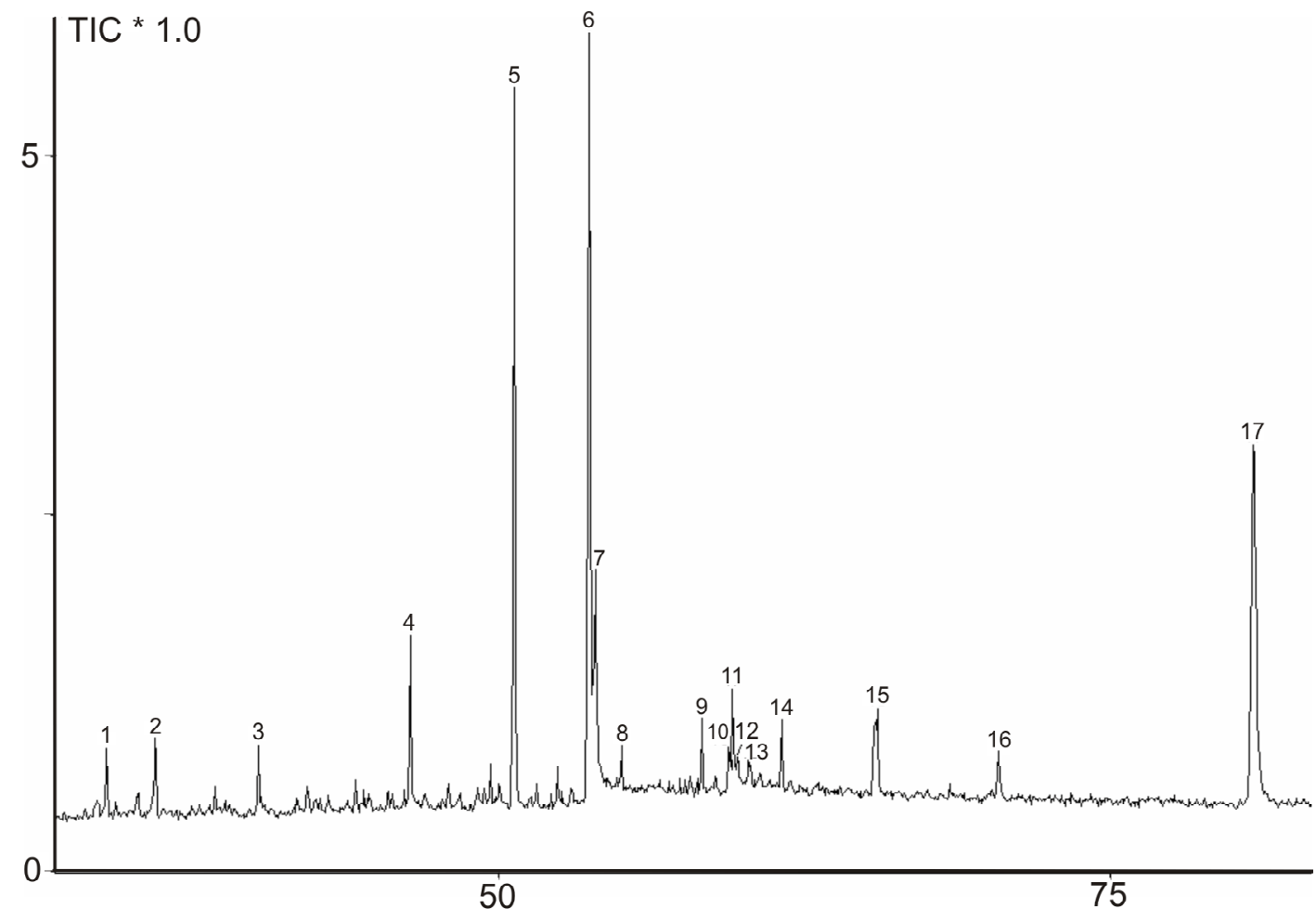

Figura 4 - Cromatograma do óleo essencial da casca de embaúba.

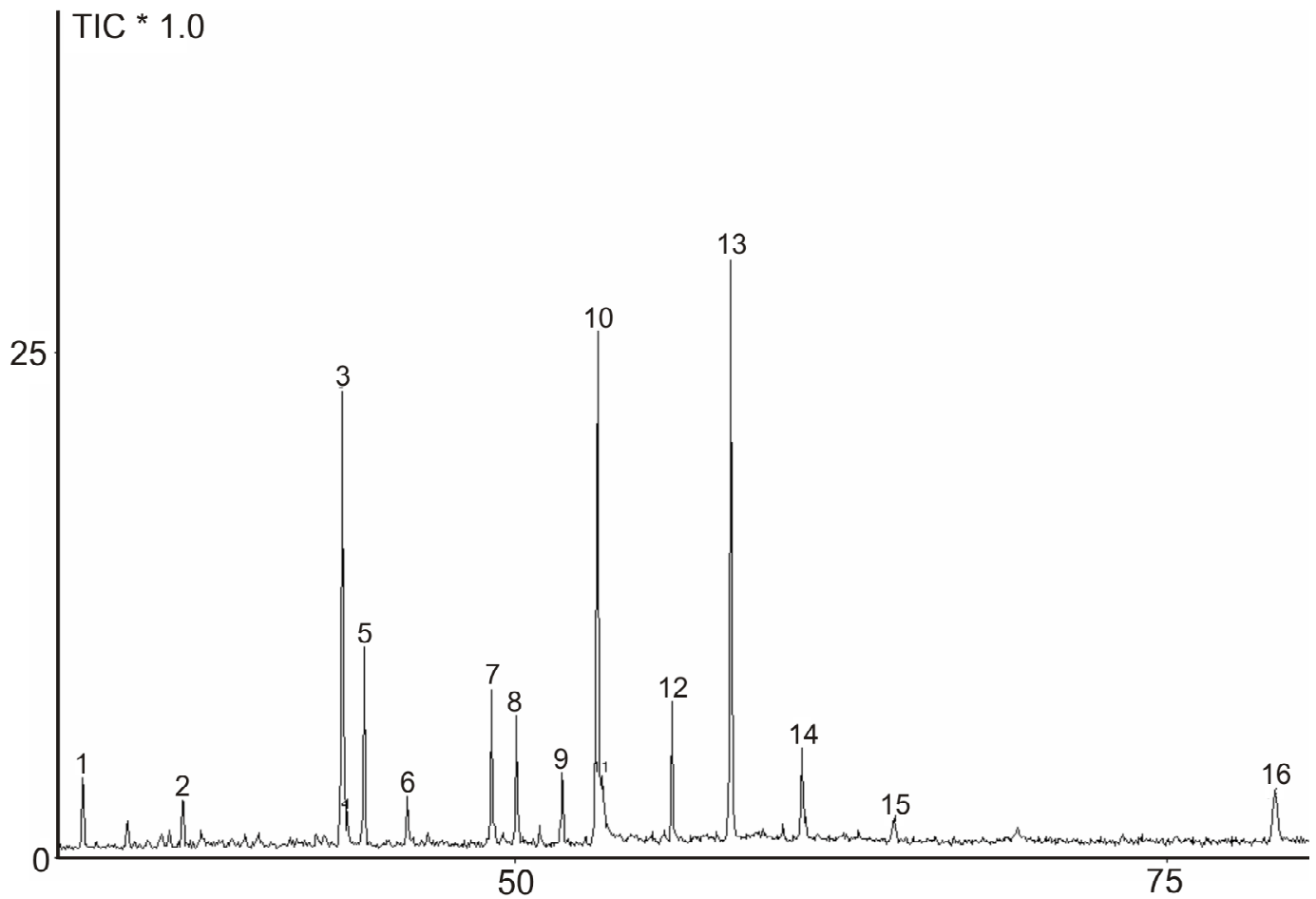

Figura 5 - Cromatograma do óleo essencial das raízes de embaúba. 
observado no extrato das raízes na concentração de 150 ppm.

Os principais constituintes voláteis identificados por CG/EM foram: no tronco: geranilacetona, ácido palmítico e alcanos de cadeia longa; na casca: geranilacetona, ácido láurico, ácido palmítico, octadecanal e alcanos de cadeia longa; e nas raízes: geranilacetona, farnesol, farnesilacetona, ácido palmítico, octadecanal e alcanos de cadeia longa.

\section{AGRADECIMENTOS}

Os autores agradecem ao Ins tituto de Química, pelo suporte de infra-estrutura, e à CAPES, pelo suporte financeiro.

\section{LITERATURA CITADA}

ADAMS, R. P. Identification of essential oil components by gas chromatography/mass spectrometry. Carol Stream: Allured Publ. Corp., 2001. 456 p.

BALBACHA, A. As plantas curam. São Paulo: Missionária, 1960. 342 p.

DUKE, S. O. et al. Natural products as sources of herbicides: current status and future trends. Weed Res., v. 40, n. 1, p. 99-111, 2000.

DUKE, S. O.; DAYAN, F. E.; RIMANDO, A. M. Natural products as tools for weed management. Proc. Jpn. Weed Sci. Soc., Suppl., p. 1-11, 1998.
ESCOLA SUPERIOR DE AGRICULTURA LUIZ DE QUEIROZ - ESALQ. Árvores medicinais - embaúba 2003. Disponível em: <http://www.esalq.usp.br/trilhas/ medicina/am26.htm>. Acesso em: 23 ago. 2004.

HASHIMOTO, M. G. Plantas brasileiras. Disponível em: $<$ http://www.brazilian-plants. com/br/embauba.html $>$.

Acesso em: 22 maio 2005.

HERNANDEZ-TERRONES, M. G. et al. Inhibition of photophosphorylation in spinach chloroplasts by the trachyloban-19-oic Acid. Pest. Biochem. Phys., v. 77, p. $12-17,2003$

HIKAWCZUK, V. J. et al. Anti-inflammatory activity of natural compounds isolated from Cecropia pachystachya. An. Asociac. Química Argentina, v. 86, n. 3-6, p. 167-170, 1998.

LORENZI, H. Árvores brasileiras: manual de identificação e cultivo de plantas. 2.ed. São Paulo: Plantarum, 1998. $352 \mathrm{p}$.

MIZUTANI, J. Selected allelochemicals. Critical Rev. Plant Sci., v. 18, n. 5, p. 653-671, 1999.

REIGOSA, M.; PEDROL, N. Allelopathy from molecules to ecosystems. Plymouth: Science Publishers, 2002. 316 p.

RICE, E. L. Allelopathy. 2. ed. New York: Academic Press, 1984. 267 p.

SIMÕES, C. et al. Farmacognosia da planta ao medicamento. Florianó polis: Universidade Federal de Santa Catarina, 2000. 822 p.

VYVYAN, J. R. Allelochemicals as leads for news herbicides and agrochemicals. Tetrahedron, v. 58, p. 1631-1646, 2002.

ZIMDHAL, R. L. Fundamentals of weed science. New York: Academic Press, 1999. 556 p. 